\title{
Reactive power control of grid-connected photovoltaic micro- inverter based on third-harmonic injection
}

\author{
Farah T. Noori' ${ }^{1}$, Turki K. Hassan ${ }^{2}$ \\ 1,2Department of Electrical Engineering, Mustansiriyah University, Iraq \\ ${ }^{1}$ Technical Institute of Baquba, Middle Technical University, Iraq
}

\begin{tabular}{l} 
Article Info \\
\hline Article history: \\
Received Aug 21, 2021 \\
Revised Sep 6, 2021 \\
Accepted Sep 13, 2021 \\
\hline
\end{tabular}

Keywords:

Current source inverter

Grid-connected

Interleaved flyback

Photovoltaic panel

Third-harmonic injection

\begin{abstract}
This paper presents four interleaved flyback DC-DC converters. Each flyback converter contains a separate maximum power point tracker (MPPT). The MPP tracker is used to collect the maximum power value from photovoltaic panel by using $(\mathrm{P} \& \mathrm{O})$ algorithm with an output of reference current. In latest years, the active third-harmonic injection circuit have received much interest, this technique contributed to getting a better quality of injection current into the utility grid and control the reactive power. For converting direct current to three-phase sinusoidal currents, a linecommutated current source inverter type (CSI) with filter is used. The developed micro-inverter of $(1000 \mathrm{~W})$ offers an expanded range of reactive power control with balanced three-phase output power and good efficiency $95.07 \%$. The effectiveness of the suggested system is clarified through the MATLAB program simulation. The system proposed in this paper has proven its effectiveness in obtaining reactive power control, nearly sinusoidal three-phase output currents and it is compared with the traditional PV microinverter system. The comparison shows that the PV micro-inverter is best in more specification than the traditional PV system such as efficiency and total harmonic distortion (THD) and the system losses.
\end{abstract}

This is an open access article under the CC BY-SA license.

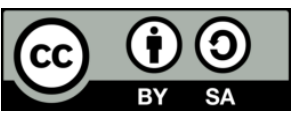

\section{Corresponding Author:}

Farah T. Noori

Department of Electrical Engineering

Mustansiriyah University

Baghdad, Iraq

Email: farahthamer3@gmail.com

\section{INTRODUCTION}

As stated by International Energy Outlook 2011 estimation, From 2006 to 2030, world electricity production increases by 77\%, increasing from 18 trillion $\mathrm{kWh}$ in 2006 to 31.8 trillion $\mathrm{kWh}$ in 2030 [1]. Renewable energies will be found for 46 per cent of global power by 2050, based on the record advanced situation referring to the intergovernmental panel on climate change emission reduction goals. Photovoltaic (PV) can play a significant role in clean energy technologies [2]. Resources of electrical energy can primarily be divided into three sets: nuclear-powered, fossil, and renewable energy resource. One of the most widelyresearched sources of renewable energy among others [3].

The arrays PV grid-connected inverter is classified into three sorts: central inverter type, string inverter type, and alternating (AC-module) (micro-inverter) type [4]. The previous technology was studied centralized inverters and string inverters, which were connected to many modules of PV. The series connection of PV modules together, defined as a string. The string panel when connected in parallel connection achieved a required power level with the centralized inverter system. This contributes to some 
drawbacks, such as the need for DC cables of high-level voltage between the PV panels and the inverter. Centralized MPP tracker (MPPT) caused more power loss, a mismatch between PV panels. If one of the PV panels in a string is shaded, it will act as an open circuit on this string, resulting in power generation. So, energy harvesting efficiency is dramatically reduced. There are several other drawbacks for using the string and central inverter systems for example a risk issue of direct current (DC) cables and there is no expandability [5].

AC module system, with ranging of low power levels of micro-inverter is used in this paper according to its several advantages such as: i) get better the energy harvesting; i) improved efficiency of the system; iii) minimize the cost of installation; iv) operation "plug-N-play"; (v) increased modularity and flexibility; (vi) enable the capacitance of the DC capacitor small [6], [7]. Micro-inverter is normally mounted at the back of the PV panel and can well be built into the photovoltaic back cover. The inverter lifetime must have a matching the photovoltaic panel lifetime. These benefits have attracted increasing interest and made them competitive for central and string inverters of a PV system.

In certain areas of the network, high PV power penetration can be seen in the network. Due to the fluctuation in photovoltaic systems, this can create serious problems in the distribution system. Instead of approaching costly grid structures in distribution networks, the reactive power ability of the inverter can be used in PV systems [8], [9]. Several topologies have been suggested and discussed for PV micro-inverters and for different ways of controlling them [5]. There are many topologies of reactive power control studied by researchers, in most of these micro-inverters are built with architecture in almost one stage and use a bridge for DC/AC conversion [4], [5]. If the micro-inverters work in the state of a unity power factor and cannot run with reactive power production, thereby failing to satisfy some electric power regulations with PV micro-inverters. Moondee and Srirattanawichaikul in [10] reactive power control study and coordinated reactive power based on the method of voltage regulation in the PV distribution grid system is presented, which is one of the traditional strategies of reactive power control.

This study proposed a three-phase micro-inverter topology, which is simulated by the MATLAB program. The proposed system consisted of PV panels each panel of $250 \mathrm{~W}$, DC-DC converter stage that includes four interleaved converters of flyback type, a circuit of third-harmonic current injection [11]. To operate the inverter, gate pulses of a square wave is required [12]. The line-commutated (CSI) with filter are suggested. Under working frequency of the isolation transformers, the structures can be classified into two main individuals: i) line-frequency isolation transformer and ii) high-frequency isolation transformer. In this paper, we essentially concentrate on configurations that use high-frequency transformers. When implementing the DC-link, the DC-DC conversion is required to provide MPP tracker and improve the DClink voltage of the PV panel to a suitable voltage value. The DC-DC topology providing galvanic isolation can be a good choice for the stage [13]. The input power generated by the PV modules ( $\left.\mathrm{P}_{\mathrm{PV}}\right)$ is used in control to be a constant and work at (MPPT) using the P\&O algorithm method, which it's simplest and basic in structure [14]. The third-harmonic current injecting circuit (3TSMC) is an advanced converter type of twostage matrix (TSMC) that is suggested for providing an option of power factor correction and output reactive power capability. The third-harmonic current injecting circuit is represented by an active power filter of single-phase. The bidirectional switch linked with each input phase is switched ON for the third-harmonic injection circuit [15]. Assuming no loss in the micro-inverter stage, so the generated power by the PV modules is the same as the average output power. Generally, a decoupling capacitor is located in the PV system to reduce the ripple in power caused at the PV-modules side by perturbation and fluctuation of PV environments [16]. The connection of decoupling capacitor in parallel with the photovoltaic panel. This paper is organized is being as: section 2 introduces topology and operating principles of the micro-inverter; section 3 presents the control of third-harmonic injection circuit; section 4 presents the control algorithm for tracking MPP; section 5 shows operation of the circuit of third-harmonic current injection; section 6 shows the simulation results to verify the presented methods; section 7 shows the final conclusion of this paper.

\section{CIRCUIT CONFIGURATION \& PRINCIPLE OF OPERATION}

\subsection{Circuit configuration}

Four PV panel (250W) with DC-DC flyback converter is connected directly to $1000 \mathrm{~W}$ three-phase micro-inverter in this proposal PV system. Figure 1, shows the configuration of the system, which involves of a photovoltaic panel, a four interleaved flyback converter in stage of DC-DC conversion, a circuit of thirdharmonic injection and CSI connected to a grid. In a DC-DC converter, four flyback converters connected in parallel and each converter contains two interleaved sub-converter shifted by $180^{\circ}$ to each other.

Small ceramic capacitor instead of large capacitor in the DC-link just to provide high-frequency input pulse current that is different than the conventional single PV input state in [6], [17]. This is the main subject of the various research teams' attention on operational issues such as the performance of the 
maximum power point tracker (MPPT), improved flyback inverters THD and the reduction of input capacitors. As shown in Figure 1, the circuit of third-harmonic current injection contains a leg of two switches connected from middle to third harmonic current inductor that is connected to one phase by the bidirectional switch. An accurate control of current in the circuit of the third-harmonic is the main part of reactive power control. The line commutated CSI includes six inverter switches. Three arms of the inverter will be shifted with 120 degrees angle to get three-phase output current.

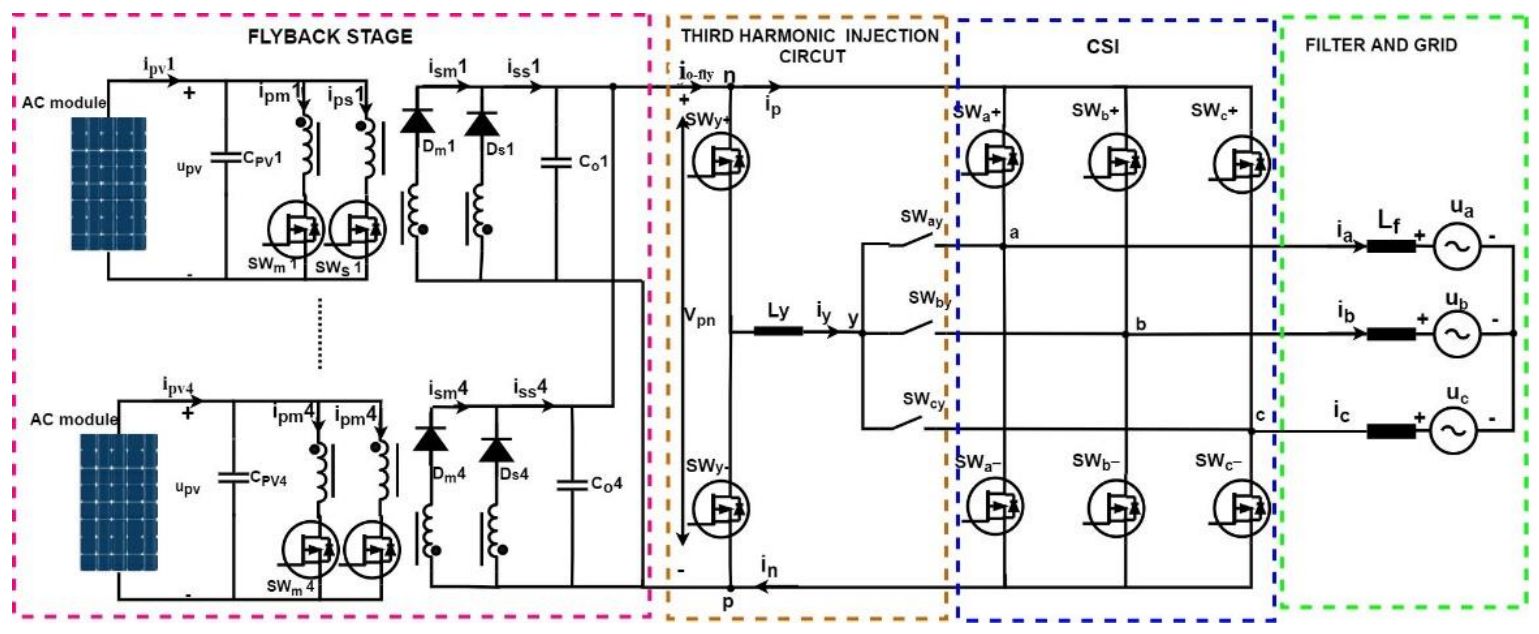

Figure 1. Micro-inverter construction schematic diagram

\subsection{Principle of operation}

Each flyback converter is operated with separate MPPT consists of two sub-converter interleaved with $180^{\circ}$ phase shift, which increases the energy harvesting, increases the efficiency of the converter, and decreases the output currents ripple. The operating principles of a third-harmonic injection circuit are described as follows: for the switches $\mathrm{Sw}_{\mathrm{a}+}, \mathrm{Sw}_{\mathrm{b}+}$, and $\mathrm{Sw}_{\mathrm{c}+}$ of an inverter, the switch is connected to the input phase with the high voltage side is held ON. For the switches $\mathrm{Sw}_{\mathrm{a}-}, \mathrm{Sw}_{\mathrm{b}-\text {, }}$ and $\mathrm{Sw}_{\mathrm{c}-\text {, }}$ the switch is connected to the input phase with the low voltage side is held ON. The switches $\mathrm{Sw}_{\mathrm{y}+}$ and $\mathrm{Sw}_{\mathrm{y}}$ is working in high switching frequency in the third-harmonic injection circuit, which can be controlled to form the thirdharmonic current $i_{y}$ flowing in the third-harmonic inductor $L_{y}$ [18], [19]. So the reactive power controlled by controlling the output power factor.

The line commutated CSI operated in synchronized with grid voltages. The DC output points $\mathrm{p}, \mathrm{n}$ and $y$ are connected to output phase voltage $a, b$ and $c$. As assume $u_{a}>u_{b}>u_{c}$ at this state, the switch in the upper arm of phase a $\left(\mathrm{Sw}_{\mathrm{a}+}\right)$ and the lower arms in phase $\mathrm{c}\left(\mathrm{Sw}_{\mathrm{c}-}\right)$ and bidirectional switch of phase $\mathrm{b}\left(\mathrm{Sw}_{\mathrm{by}}\right)$ are operated in $\mathrm{ON}$ state, to generate six pulses of gating signals across DC-link voltage as shown in Table 1.

Table 1. CSI switching states

\begin{tabular}{lllllllllll}
\hline$\theta_{\mathrm{sa}}$ & Sector & $\mathrm{Sw}_{\mathrm{ay}}$ & $\mathrm{Sw}_{\mathrm{by}}$ & $\mathrm{Sw}_{\mathrm{cy}}$ & $\mathrm{Sw}_{\mathrm{a}+}$ & $\mathrm{Sw}_{\mathrm{a}-}$ & $\mathrm{Sw}_{\mathrm{b}+}$ & $\mathrm{Sw}_{\mathrm{b}-}$ & $\mathrm{Sw}_{\mathrm{c}+}$ & $\mathrm{Sw}_{\mathrm{c}-}$ \\
\hline $0-\pi / 3$ & One & 0 & 1 & 0 & 1 & 0 & 0 & 0 & 0 & 1 \\
$\pi / 3-2 \pi / 3$ & Two & 1 & 0 & 0 & 0 & 0 & 1 & 0 & 0 & 1 \\
$2 \pi / 3-\pi$ & Three & 0 & 0 & 1 & 0 & 1 & 1 & 0 & 0 & 0 \\
$\pi-4 \pi / 3$ & Four & 0 & 1 & 0 & 0 & 1 & 0 & 0 & 1 & 0 \\
$4 \pi / 3-5 \pi / 3$ & Five & 1 & 0 & 0 & 0 & 0 & 0 & 1 & 1 & 0 \\
$5 \pi / 3-2 \pi$ & Six & 0 & 0 & 1 & 1 & 0 & 0 & 1 & 0 & 0 \\
\hline
\end{tabular}

If the three-phase output voltages follow $u_{a}>u_{b}>u_{c}$ (referred to sector one) and in this topology includes just one sub-converter working in the continuous conduction state. Figure 2, shows the first stage equivalent circuit. When the converter switch $\mathrm{Sw}_{\mathrm{m} 1}$ in the $\mathrm{ON}$ operating state and the diode $\mathrm{D}_{\mathrm{m} 1}$ in reverse direction state, so the flyback primary current $i_{\mathrm{pm} 1}$ is linearly increased at the same time the secondary current $i_{\mathrm{sm} 1}$ is zero. The magnetizing current $i_{\mathrm{mm} 1}$ is represented in (1) in this stage a flyback transformer winding stored energy.

$$
L_{m 1} \frac{d i_{m m 1}}{d t}=u_{p v}
$$


Where, $\mathrm{L}_{\mathrm{m} 1}$ : is the magnetizing inductance of flyback transformer $\mathrm{u}_{\mathrm{pv}}$ : is the voltage of photovoltaic panel

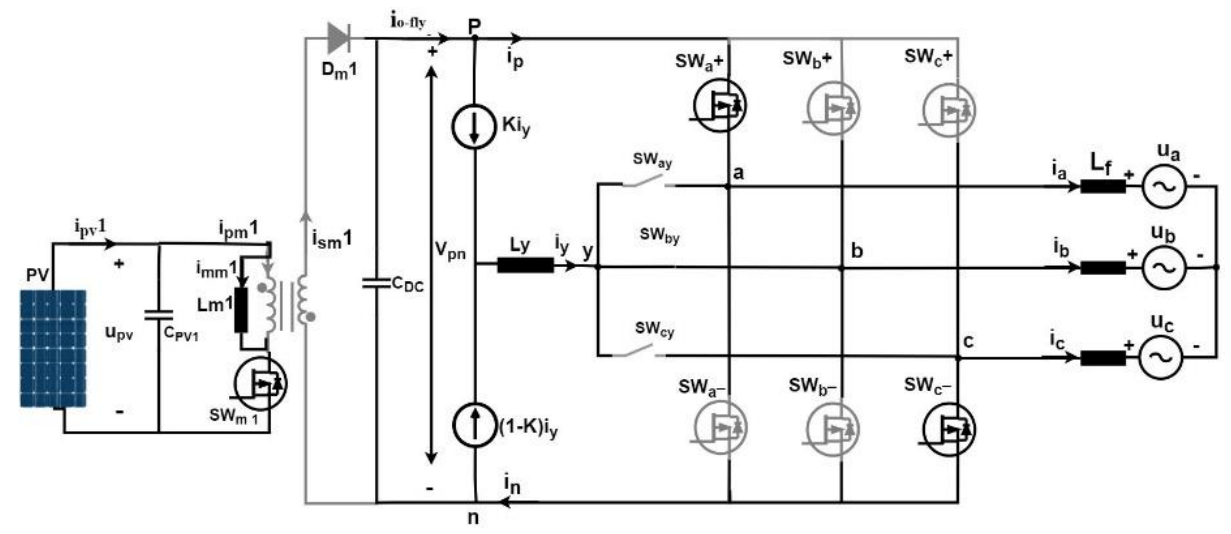

Figure 2. The proposed AC module's equivalent circuit of three-phase micro-inverter (first operating stage)

An equivalent circuit of the second stage of the operation is shown in Figure 3. In which the converter switch $\mathrm{Sw}_{\mathrm{m} 1}$ in OFF operating state and the diode $\mathrm{D}_{\mathrm{m} 1}$ in a forward state, so the input current $\mathrm{i}_{\mathrm{pm} 1}$ is zero and the secondary current is linearly reduced. The magnetizing current $i_{\mathrm{mm} 1}$ is described in (2), the energy stored in a flyback transformer winding is released to a secondary side of transformer.

$$
L_{m 1} \frac{d i_{m m 1}}{d t}=\frac{-u_{p n}}{N}
$$

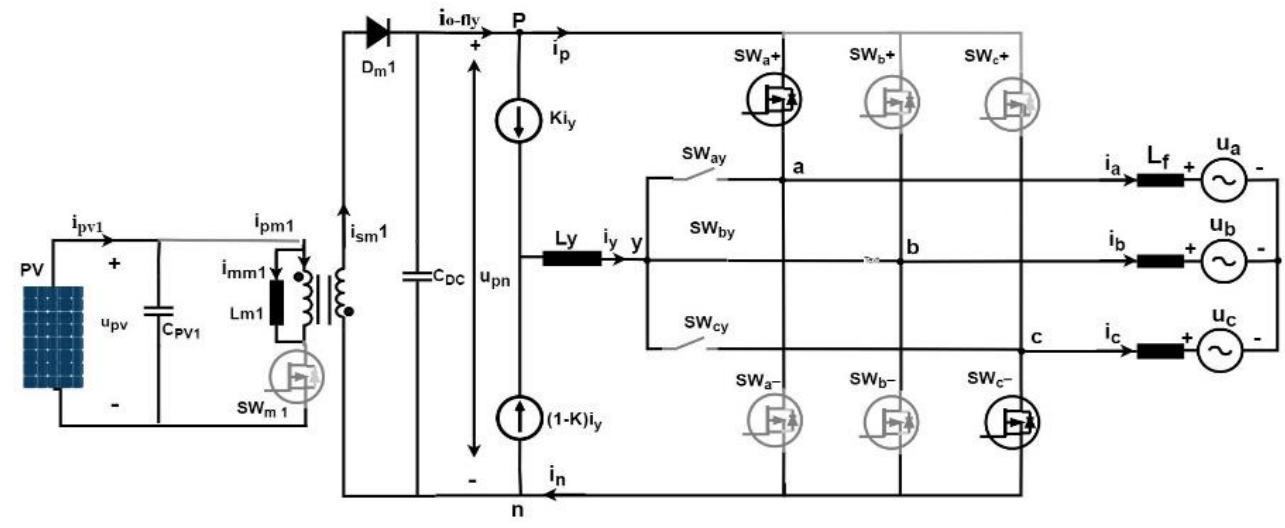

Figure 3. The proposed AC module's equivalent circuit of three phase micro-inverter (second operating stage)

The DC-link voltage is described by (3).

$$
u_{p n}=u_{a}-u_{c}
$$

Where $\mathrm{N}$ : is the turn ratio of flyback transformer.

The secondary current $i_{\text {sm1 }}$ and output current is obtained in (4).

$i_{s m 1=i_{o}}=\frac{i_{m m 1}}{N}$

Figure 4, shows the key waveforms during a switching time $\mathrm{T}_{\mathrm{s}}$ of a micro-inverter operational, where $f_{s}$ is a switching frequency of micro-inverter, $k$ is a duty ratio of the third-harmonic switch $\mathrm{Sw}_{\mathrm{y}+}$ and $\mathrm{d}$ is a duty ratio of the flyback switch $\mathrm{Sw}_{\mathrm{m} 1}$. The micro-inverter waveforms are shown in Figure 5. Figure 6, 
shows the gating signal of bidirectional switches and CSI switches. It is possible to achieve sinusoidal currents injected into the grid and control the reactive power.

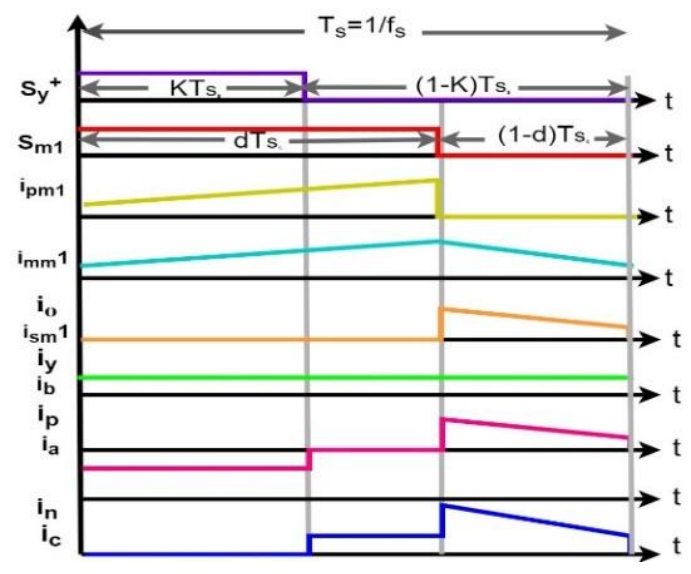

Figure 4. Key waveforms during a switching time

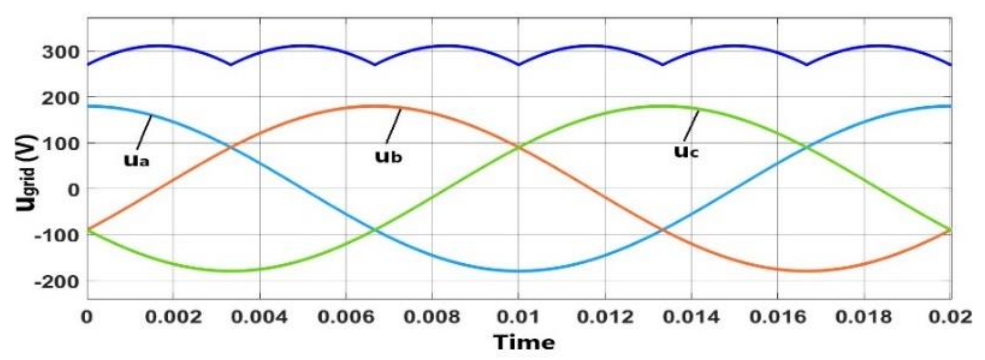

Figure 5. Output voltages and DC link voltage of proposed micro-inverter

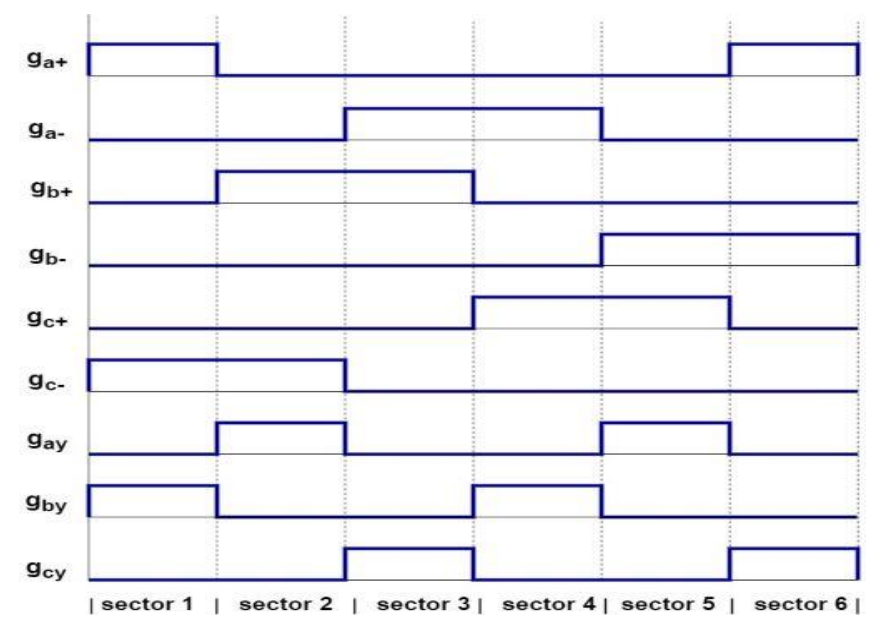

Figure 6. Gating signals of the proposed micro-inverter

\section{THIRD-HARMONIC INJECTION CONTROL}

If every one of the sub-converter is worked separately and just one of the sub-converter is taken in a DC-DC flyback converter stage for this topology. The three-phase output voltages are symmetrically operated, and if the output voltages vector is set in sector one, so the reference three-phase output voltages are assumed by: 


$$
\left[\begin{array}{c}
u_{a}=U_{m} \cos \left(\theta_{a}\right) \\
u_{b}=U_{m} \cos \left(\theta_{a}-\frac{2 \pi}{3}\right) \\
u_{c}=U_{m} \cos \left(\theta_{a}+\frac{2 \pi}{3}\right)
\end{array}\right]
$$

Where $U_{m}$ : is the magnitude of output phase voltages.

Category the output voltages by the instantaneous voltage value relations as can be seen is being as:

$$
\left[\begin{array}{c}
u_{\max }=\max \left(u_{a}, u_{b}, u_{c}\right) \\
u_{\text {mid }}=\operatorname{mid}\left(u_{a}, u_{b}, u_{c}\right) \\
u_{\min }=\min \left(u_{a}, u_{b}, u_{c}\right)
\end{array}\right]
$$

Where $\mathrm{u}_{\max }, \mathrm{u}_{\text {mid }}$ and $\mathrm{u}_{\min }$ characterize the maximum voltage, the medium voltage, and the minimum voltage among the three-phase output voltages [18].

The DC-link voltage is described in (7) related to the maximum and minimum voltage in sector 1.

$$
u_{p n}=u_{\max }-u_{\min }=u_{a}-u_{c}
$$

In a period of each switching, considering the voltage-second balance of $\mathrm{L}_{\mathrm{y}}$, a duty ratio equation can be shown as [18]:

$$
\begin{aligned}
& {\left[\begin{array}{c}
u_{\text {mid }=k u_{\max }+k^{\prime}} u_{\min } \\
k+k^{\prime}=1
\end{array}\right]} \\
& k=\frac{u_{\operatorname{mid}}-u_{\min }}{u_{\max }-u_{\min }} \\
& k^{\prime}=\frac{u_{\max }-u_{\operatorname{mid}}}{u_{\max }-u_{\min }}
\end{aligned}
$$

Where $\mathrm{k}$ and $\mathrm{k}^{\prime}$ are the duty ratios of the switches $\mathrm{Sw}_{\mathrm{y}+}$ and $\mathrm{Sw}_{\mathrm{y}-}$ at steady state, respectively.

The duty ratio is obtained in (11) according to magnetizing inductor $\mathrm{L}_{\mathrm{m}}$, voltage-second balance.

$$
d=\frac{u_{p n}}{N u_{p v}+u_{p n}}
$$

Assume the output currents are in sinusoidal shape and a power factor is regulated and operation is taken in sector one, it's got that the current $i_{y}$ is the same value of current $i_{b}$ can be obtained in (12) [18].

$$
\left[\begin{array}{c}
i_{y}=i_{b}=I_{p m} \cos \left(\theta_{a}-\frac{2 \pi}{3}\right)+I_{q m} \sin \left(\theta_{a}-\frac{2 \pi}{3}\right) \\
=G U_{m} \cos \left(\theta_{a}-\frac{2 \pi}{3}\right)+I_{q m} \sin \left(\theta_{a}-\frac{2 \pi}{3}\right) \\
=\frac{G U_{m} \cos \left(\theta_{a}-\frac{2 \pi}{3}\right)}{\cos \varphi} \\
\tan \varphi=\frac{I_{q m}}{I_{p m}}
\end{array}\right]
$$

Where $\mathrm{I}_{\mathrm{pm}}$ is the amplitudes of the output current active component and $\mathrm{I}_{\mathrm{qm}}$ is the amplitudes of the reactive component of the output currents, and $\mathrm{G}=2 \mathrm{P} / 3 \mathrm{U}_{\mathrm{m}}$ represent the equivalent input conductance, $\mathrm{P}$ is the output active power $\varphi$ is the desired phase displacement angle. Phase a output current is given in (13).

$$
i_{a}=\overline{l_{s m 1}}-k i_{y}
$$

Where $\overline{\mathrm{s}_{\mathrm{sm} 1}}$ : is the average output current of a flyback converter.

According to sector one, the voltage of the DC-link is equal to $\mathrm{u}_{\max }-\mathrm{u}_{\min }$ voltage is equal to $\mathrm{u}_{\mathrm{ac}}$. And the duty ratio is $\mathrm{u}_{\mathrm{bc}} / \mathrm{u}_{\mathrm{ac}} \mathrm{i}_{\mathrm{a}}$ is shown in (14) [18].

$$
i_{a=\frac{G U_{m} \cos \left(\theta_{a}+\varphi\right)}{\cos \varphi}}
$$

And the phase c output current is obtained in (15). 


$$
i_{c}=\frac{G U_{m} \cos \left(\theta_{a}+\frac{2 \pi}{3}+\varphi\right)}{\cos \varphi}
$$

\section{THE MPP TRACKING CONTROL OF THE PV PANEL}

The photovoltaic system uses photovoltaic energy effectively with MPP tracker. PV system's MPPT depends on and tracks with environmental conditions. Among the multiple MPPT methods, the P\&O algorithm is the most commonly used due to its simple design and it is not difficult to achieve. However, the traditional P\&O technique is slow in operation also it is suffering from steady-state fluctuation [3], [20], [21]. The PV panel of the micro-inverter must still in tracking this working point whenever it varies according to the change of sunlight, and also when shading in partial, to reach this effect. The MPPT can be done by controlling the PV current. The P\&O MPP tracker algorithm is built on PV current control is taken in this work for the three-phase micro-inverter because of its benefits with the great performance and small implementing efforts. Current perturbation is taken into account in this method instead of the perturbation of voltage to increase the speed performance of the MPP tracking [4], [22].

Figure 7, Shows the block diagram of developed micro-inverter MPP tracker, $\mathrm{G}_{\mathrm{f} 1}(\mathrm{~s})$ is the transfer function of first sub-converter and $\mathrm{G}_{\mathrm{f} 2}(\mathrm{~s})$ is the second sub-converter. As shown the outer loop of the controller is track the MPP of the PV by measuring photovoltaic voltage and photovoltaic current of the system and control the reference current to adjust the path of the perturbation toward MPP depending on the previous path point and the change in the photovoltaic panel power while the internal control loop with PIcontroller is used to control the measured current of a PV with the reference current from MPP tracker. The $\mathrm{d}^{*}$ is a duty ratio of a flyback converter switch in continuous mode operation at steady state is feedforward with the output of the internal loop to increase the dynamic tracking speed. Where $\mathrm{d}^{*}$ is found by the DCLink voltage $\left(\mathrm{u}_{\mathrm{pn}}\right)$ and the photovoltaic panel voltage $\left(\mathrm{v}_{\mathrm{pv}}\right)$.

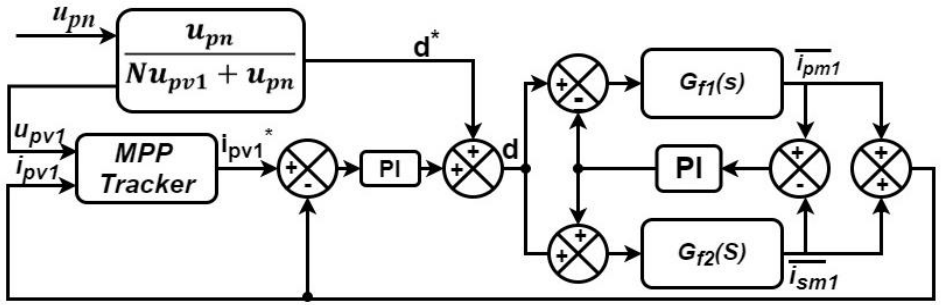

Figure 7. Block of the MPP tracker of the photovoltaic system

\section{THE THIRD-HARMONIC INJECTION CIRCUIT CONTROL}

An operation of the circuit of third-harmonic current injection is related to injecting of a suitable current value of third-harmonic $i_{y}$. So, the third-harmonic current control $i_{y}$ is important in design the circuit of a third-harmonic injection. The aim is to control the actual third-harmonic current $i_{\mathrm{y}}$ which track reference current $\mathrm{i}_{\mathrm{y}}{ }^{*}[23]$. Thus $\mathrm{P}_{\mathrm{o}}{ }^{*}$ and $\mathrm{i}_{\mathrm{y}}{ }^{*}$ should be found firstly as shown in Figure 8.

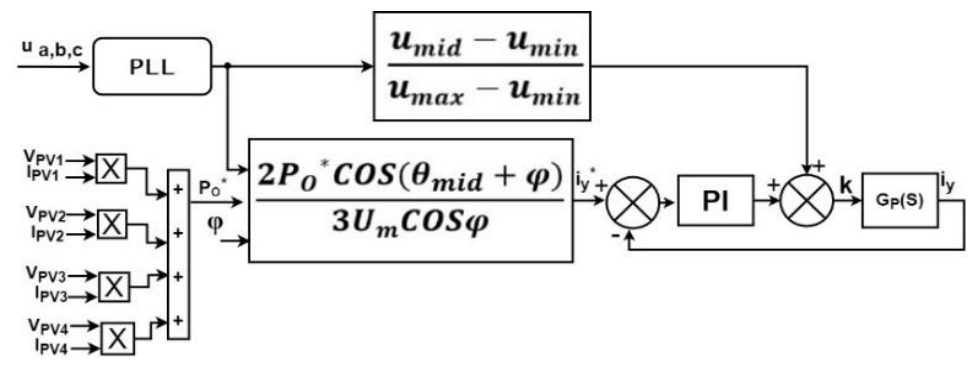

Figure 8. Block diagram of third-harmonic injection circuit design for micro-inverter

The third-harmonic injection circuit mathematical model can be obtained is being as: 
$u_{L y}=L_{y} \frac{d i_{y}}{d t}$

As shown from (16) that the current in the inductor of a third-harmonic injection can be regulated by change in the voltage of third-harmonic inductor $\mathrm{u}_{\mathrm{Ly}}$. Figure 8, show the control block of the circuit of thirdharmonic injection and parameters of design the PV micro-inverter system, where $\theta_{\text {mid }}$ is the output phase voltage angle of a medium value, $\mathrm{P}_{\mathrm{o}}{ }^{*}$ is the sum of PV powers reference from PV panels and $\mathrm{G}_{\mathrm{p}}(\mathrm{s})$ is a transfer function of the third-harmonic current injection circuit [5]. Parameters of this micro-inverter system is obtained in Table 2. The PV panel specification used in this design is shown in Table 3.

Table 2. Micro-inverter system specifications

\begin{tabular}{ll}
\hline \multicolumn{1}{c}{ Parameters } & \multicolumn{1}{c}{ Values } \\
\hline Total power rating & $1000 \mathrm{~W}$ \\
Grid voltage (Line-line) & $220 \mathrm{~V}(\mathrm{rms})$ \\
Output frequency of the inverter & $50 \mathrm{~Hz}$ \\
Frequency of switching & $50 \mathrm{kHz}$ \\
The magnetizing inductance of flyback transformer & $54 \mu \mathrm{H}$ \\
Turn ratio & 6.5 \\
Filter inductance & $500 \mu \mathrm{H}$ \\
Capacitance filter & $5 \mathrm{mF}$ \\
Third harmonic inductor & $3 \mathrm{mH}$ \\
\hline
\end{tabular}

Table 3. PV panel specification

\begin{tabular}{lll}
\hline \multicolumn{1}{c}{ Parameters } & Values & Unit \\
\hline Number of cells & 60 & \\
Light intensity & 1000 & $\mathrm{~W} / \mathrm{m} 2$ \\
Temperature & 25 & ${ }^{\circ} \mathrm{C}$ \\
Maximum power point voltage & 30.7 & $\mathrm{~V}$ \\
Maximum power point current & 8.15 & $\mathrm{~A}$ \\
Short circuit current & 8.66 & $\mathrm{~A}$ \\
Open circuit voltage & 37.3 & $\mathrm{~V}$ \\
\hline
\end{tabular}

\section{SIMULATION RESULTS}

The simulation is discussed in this part to check the feasibility of the suggested control schemes of a three-phase grid-connected micro-inverter system. The MATLAB software program is used in this simulation. Figure 9, shows the waveforms of half power rated condition of micro-inverter, at which the output currents of the PV panel are set with PV power of each panel at $\mathrm{P}_{\mathrm{PV} 1}=0 \mathrm{~W}, \mathrm{P}_{\mathrm{PV} 2}=125 \mathrm{~W}, \mathrm{P}_{\mathrm{PV} 3}=125$ $\mathrm{W}$, and $\mathrm{P}_{\mathrm{PV} 4}=250 \mathrm{~W}$ respectively. The wanted output displacement angle $\varphi$ is 0 . Figure 9 (a) shows the output voltage and output current of phase a. Figure 9 (b) shows the three-phase output current. As shown, the three-phase currents are near to sinusoidal waveform shape and in the equal phase with the three-phase output voltage. So, it's clear that the system is operating at unity power factor and show the output power of micro-inverter at $500 \mathrm{~W}$, which means each one of the flyback converters is operating individually by its MPP tracker. The output current total harmonic distortion (THD) is $5.37 \%$.

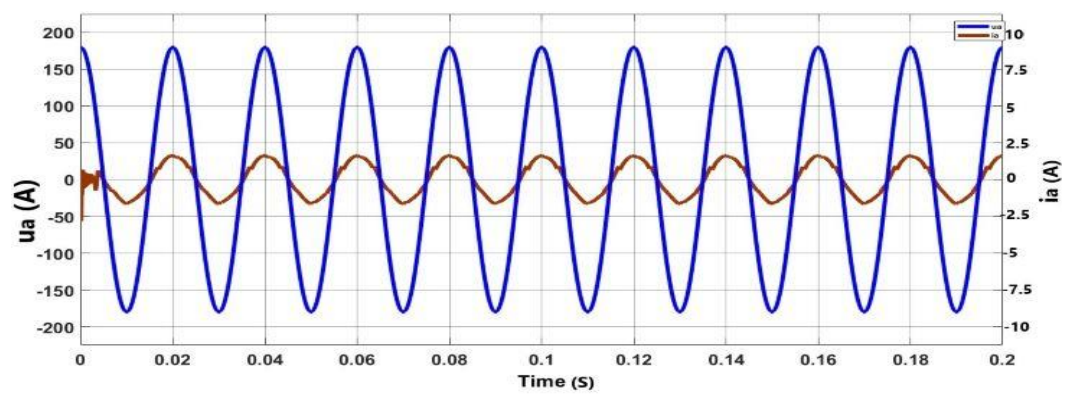

(a)

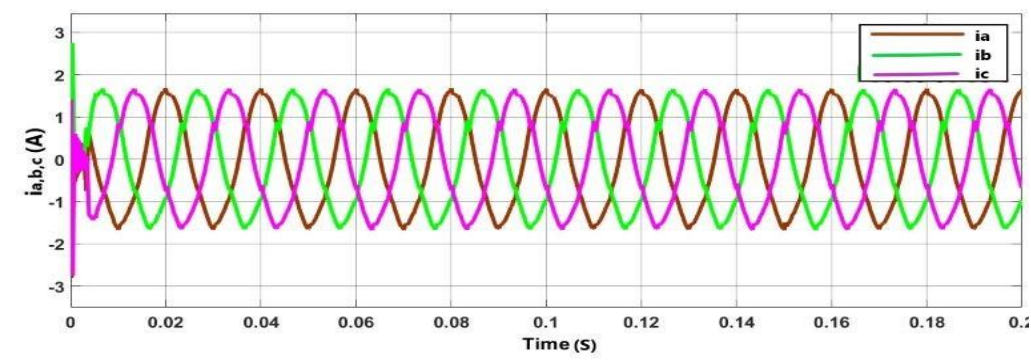

(b)

Figure 9. Waveforms of the micro-inverter working at $500 \mathrm{~W}$ condition; (a) output phase voltage and output phase current, (b) three-phase output currents 
The measured third-harmonic current $i_{y}$ and the reference of third-harmonic current $i_{y}{ }^{*}$ at half power rated shows in Figure 10. The Figure 11, shows the waveforms of the full rated power condition of the microinverter, at which the output currents of the PV panel are set with PV power of each panel at PPV1 $=250 \mathrm{~W}$, PPV2 $=250 \mathrm{~W}$, PPV3 $=250 \mathrm{~W}$, and PPV4 $=250 \mathrm{~W}$ respectively. Also, the wanted output displacement angle $\varphi$ is 0 . Figure 11 (a), shows the output voltage and output current of phase a. Figure 11 (b) shows the three-phase output current. The three-phase currents are nearest to sinusoidal waveform shape and in the equal phase with a three-phase output voltage. In this condition the output power of micro-inverter at $1000 \mathrm{~W}$ and unity power factor. THD of output current is $2.54 \%$.

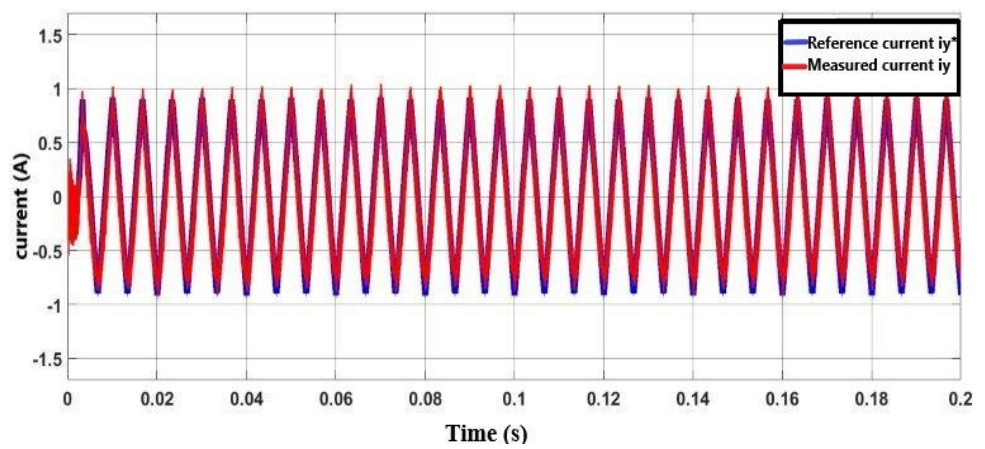

Figure 10. Measured and reference injected third-harmonic currents at $500 \mathrm{~W}$

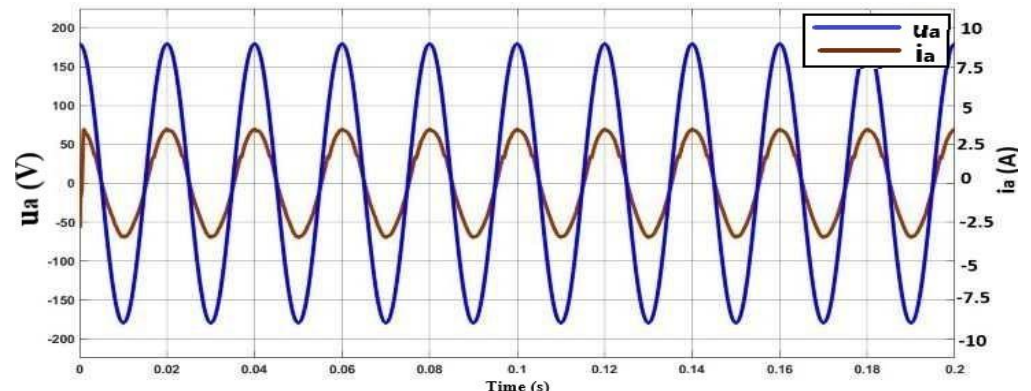

(a)

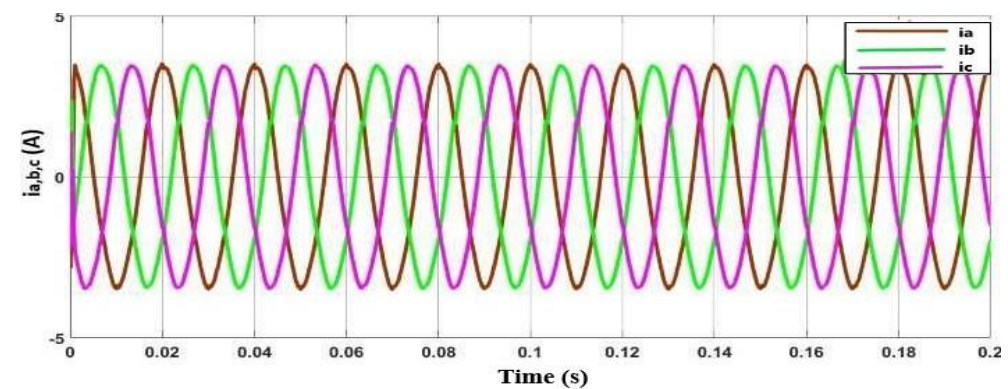

(b)

Figure 11. The micro-inverter waveforms working in full-power condition; (a) output phase voltage and output phase current, (b) three-phase output currents

The measured third-harmonic current $\mathrm{i}_{\mathrm{y}}$ and the reference of third-harmonic current $\mathrm{i}_{\mathrm{y}}{ }^{*}$ at full power rated $(1000 \mathrm{~W})$ shows in Figure 12. The Figure 13, states that the suggested micro-inverter system can control the reactive power and the output current near sinusoidal. The figure shows the micro-inverter operated at the rated power of $1000 \mathrm{~W}$ and the reactive power of 268 Var and the expected displacement phase angle is $15^{\circ}$. The THD of output current is $2.9 \%$. Figure 13 (a) shows the output voltage with an output current of phase a. Figure 13 (b) shows the three-phase output currents. 
The injected third-harmonic current (measured and reference) at voltage at 268 Var output reactive power and phase displacement angle of $15^{\circ}$ shows in Figure 14. The Figure 15, shows the micro-inverter operated at rated power of $1000 \mathrm{~W}$ and reactive power of $577 \mathrm{Var}$ and displacement phase angle of $30^{\circ}$. The THD of output current is $5.43 \%$. Figure 15 (a) shows the output voltage and output current of phase a. Figure 15 (b) shows the three-phase output currents.

The injected third-harmonic current (measured and reference) at 577 Var output reactive power and phase displacement angle of $30^{\circ}$ shows in Figure 16. These results are compared with other reactive power searches techniques which are not used third-harmonic current injection such as [24], [25], this proposed system obtained good performance and simplicity in construction. The dynamic response of irradiation changes from $1000 \mathrm{~W} / \mathrm{m}^{2}$ to $750 \mathrm{~W} / \mathrm{m}^{2}$ during system operation shows in Figure 17 (a) three-phase output currents during the change shows in Figure 17 (b) and their peak value equal to $3.5 \mathrm{~A}$ at $1000 \mathrm{~W} / \mathrm{m}^{2}$ and equal to $2.57 \mathrm{~A}$ at $750 \mathrm{~W} / \mathrm{m}^{2}$. The third-harmonic current injection circuit during irradiation change from $1000 \mathrm{~W} / \mathrm{m}^{2}$ to $750 \mathrm{~W} / \mathrm{m}^{2}$, Iy is change from (1.96 A to $\left.1.4 \mathrm{~A}\right)$ shows in Figure 18.

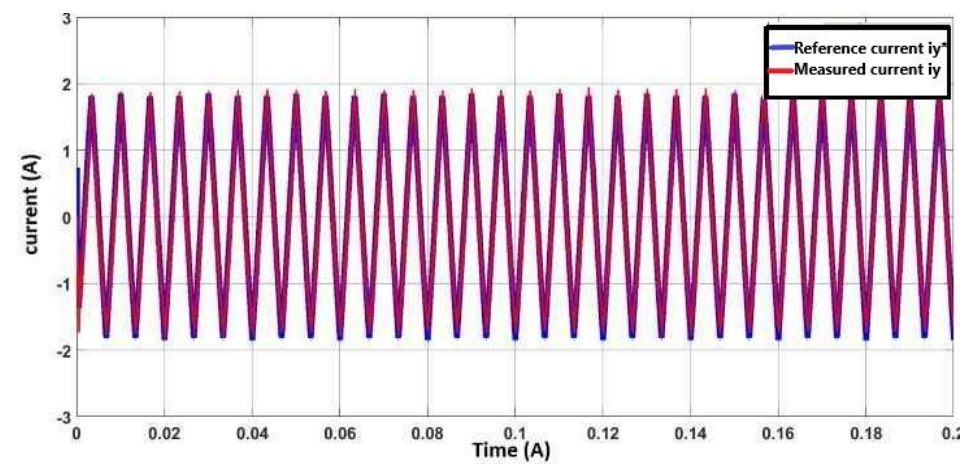

Figure 12. Measurement and reference injected third-harmonic currents at $1000 \mathrm{~W}$

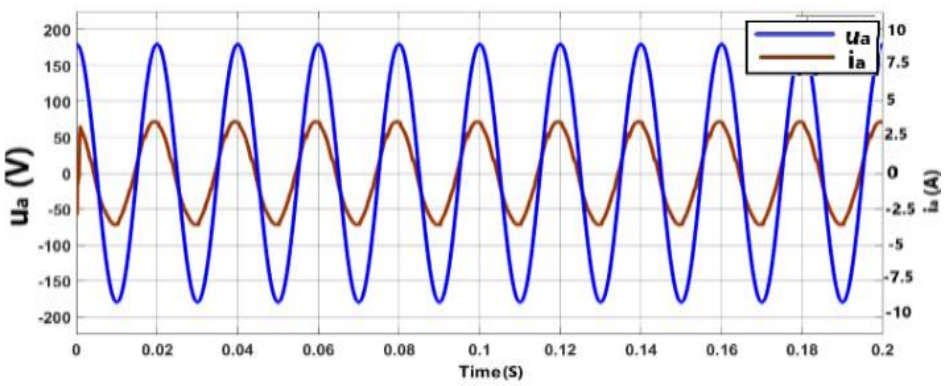

(a)

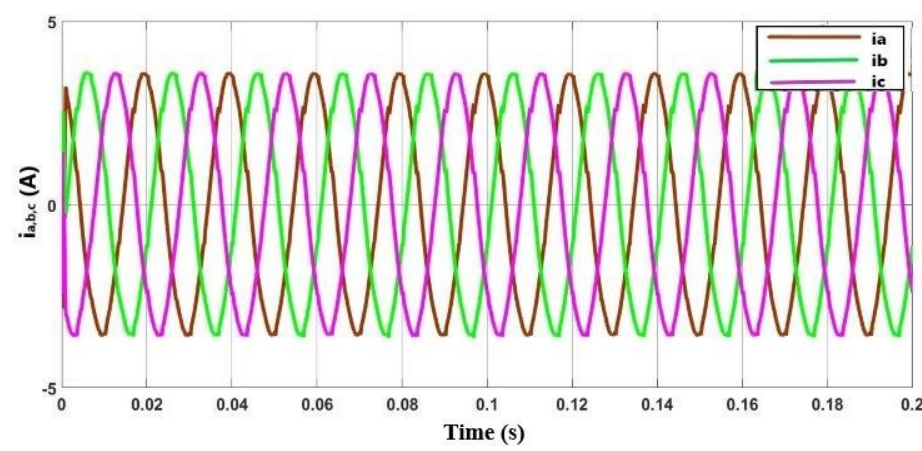

(b)

Figure 13. Micro-inverter waveforms with output reactive power of 268 Var and phase displacement angle $15^{\circ}$; (a) output phase voltage and output phase current, (b) three-phase output currents 


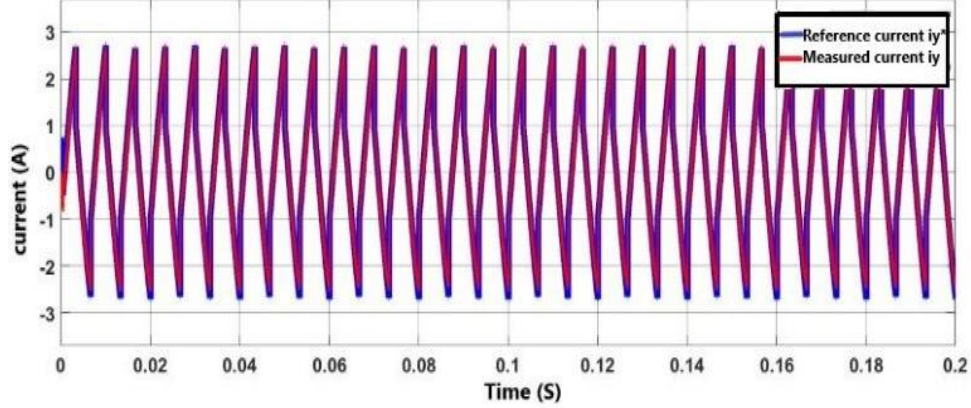

Figure 14. Injected (measured and reference) third-harmonic currents at 268 Var output reactive power and phase displacement of angle of $15^{\circ}$

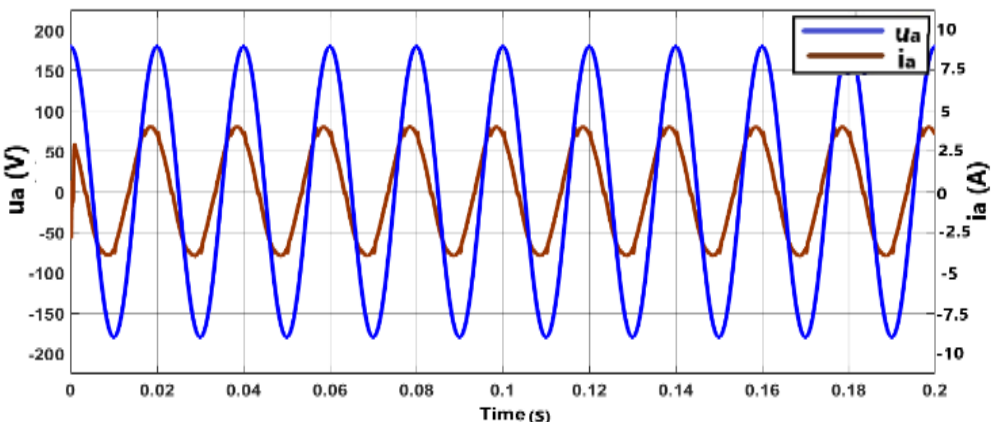

(a)

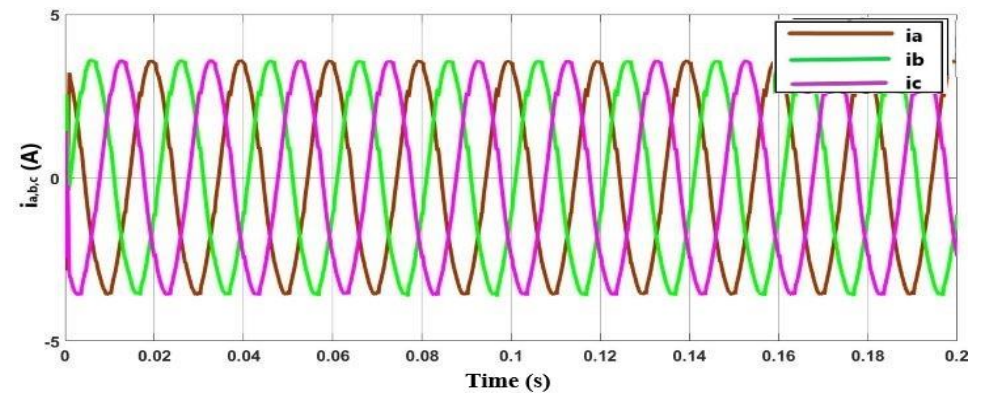

(b)

Figure 15. Micro-inverter waveforms with output reactive power of 577 Var and phase displacement angle $30^{\circ}$; (a) output phase voltage and output phase current, (b) three-phase output currents

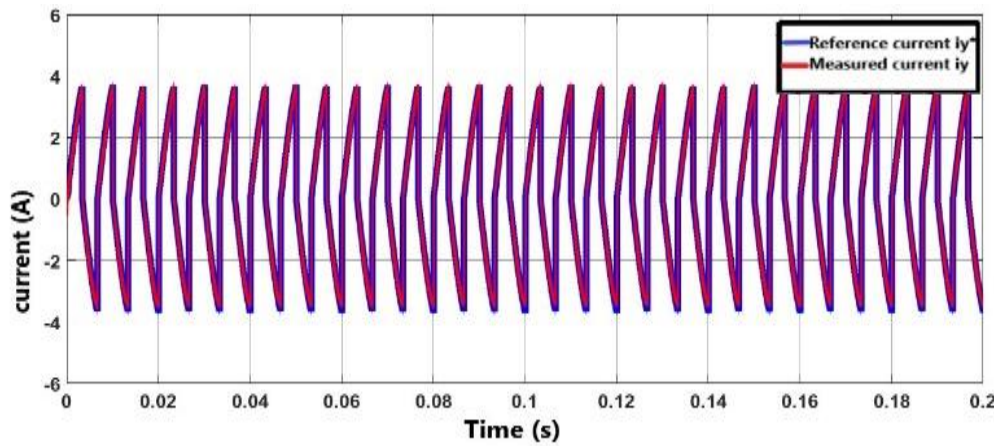

Figure 16. Injected third-harmonic current (measured and reference) measured at 577 Var output reactive power and phase displacement angle of $30^{\circ}$ 


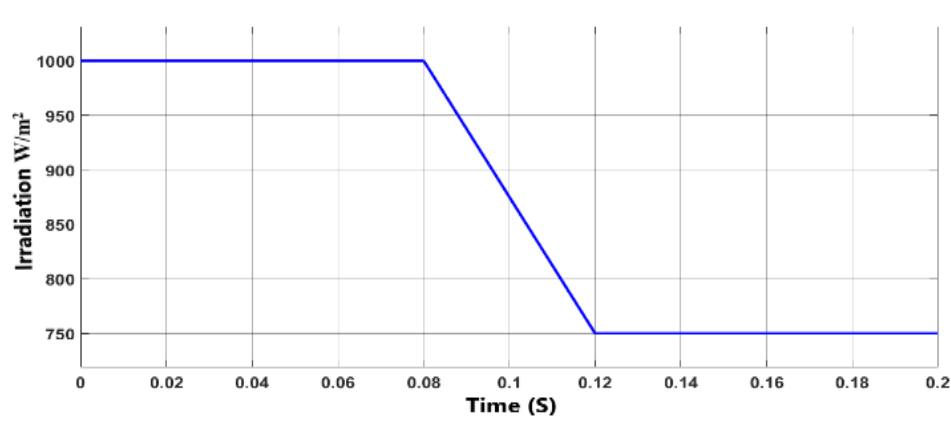

(a)

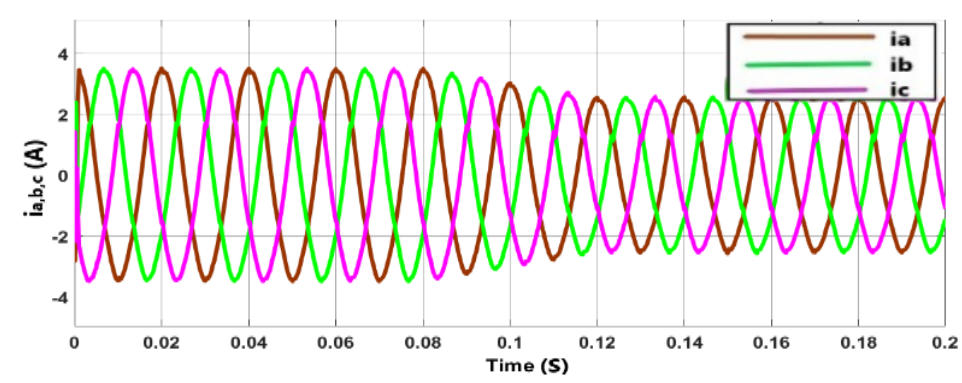

(b)

Figure 17. These figures are, (a) solar cells irradiation changes from $1000 \mathrm{~W} / \mathrm{m}^{2}$ to $750 \mathrm{~W} / \mathrm{m}^{2}$, (b) three-phase output currents

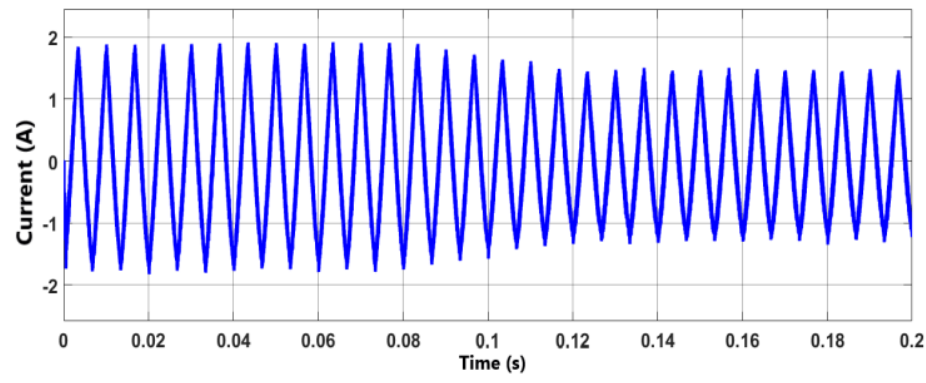

Figure 18. Third-harmonic current through irradiation change from $1000 \mathrm{~W} / \mathrm{m}^{2}$ to $750 \mathrm{~W} / \mathrm{m}^{2}$

\section{CONCLUSION}

This paper proposed a new topology concept of a photovoltaic system, which presented the capability of control the reactive power of a three-phase grid-connected PV micro-inverter. Four interleaved flyback converters are used, an individual MPP tracker is controlled for each flyback converter. The circuit of the thirdharmonic injection provides the control for the third harmonic current injection hence, an expected power factor correction is achieved. A line-commutated CSI inverter is designed for converting the direct current from the flyback converter to a three-phase output current, which can be injected into the grid through a three-phase filter. The micro-inverter is can be operated with full power level $(1000 \mathrm{~W})$, lower active power and different reactive power level. The simulation results obtained that suggested PV micro-inverter achieved these advantages: i) nearly sinusoidal output currents; ii) an expanded range of reactive power control; iii) high efficiency 95.07\%; iv) using of flyback converter makes isolation between converter and PV panels; v) reduction of DC-link capacitors, vi) more reliability and balanced output current. These advantages can be achieved when compared with the traditional reactive power topology of a photovoltaic system. So, this proposed system is good for AC module system applications and the micro-inverter can inject active and reactive power into the grid of $220 \mathrm{~V}$ by controlling the third-harmonic injection current.

\section{REFERENCES}

[1] F. Gerali, "Energy Information Administration," International energy outlook, 2011.

[2] International Energy Agency, "Energy technology perspectives 2008-scenarios and strategies to 2050," [Online]. Available: www.eia.org. 
[3] E. Kabalci, G. Gokkus, and A. Gorgun, "Design and implementation of a PI-MPPT based Buck-Boost converter," 2015 7th International Conference on Electronics, Computers and Artificial Intelligence (ECAI), 2015, pp. SG-23SG-28, doi: 10.1109/ECAI.2015.7301194.

[4] S. B. Kjaer, J. K. Pedersen, and F. Blaabjerg, "A review of single-phase grid-connected inverters for photovoltaic modules," IEEE Trans. on Ind. App., vol. 41, no. 5, pp. 1292-1306, Sept.-Oct. 2005, doi: 10.1109/TIA.2005.853371.

[5] S. B. Kjaer, J. K. Pedersen, and F. Blaabjerg, "Power inverter topologies for photovoltaic modules-a review," Conference Record of the 2002 IEEE Industry Applications Conference. 37th IAS Annual Meeting (Cat. No.02CH37344), 2002, pp. 782-788 vol.2, doi: 10.1109/IAS.2002.1042648.

[6] Y. Li and R. Oruganti, "A Low Cost Flyback CCM Inverter for AC Module Application," IEEE Transactions on Power Electronics, vol. 27, no. 3, pp. 1295-1303, March 2012, doi: 10.1109/TPEL.2011.2164941.

[7] E. Bielskis, A. Baskys, and G. Valiulis, "Controller for the grid-connected microinverter output current tracking," Symmetry (Basel), vol. 12, no. 1, p. 112, January 2020, doi: 10.3390/sym12010112.

[8] M. Kolhe and M. Rasul, "3-Phase grid-connected building integrated photovoltaic system with reactive power control capability,” Renewable Energy, vol. 154, pp. 1065-1075, 2020, doi: 10.1016/j.renene.2020.03.075.

[9] A. Y. Mohammed, F. I. Mohammed, and M. Y. Ibrahim, "Grid connected Photovoltaic system," 2017 International Conference on Communication, Control, Computing and Electronics Engineering (ICCCCEE), 2017, pp. 1-5, doi: 10.1109/ICCCCEE.2017.7867659.

[10] W. Moondee and W. Srirattanawichaikul, "Study of Coordinated Reactive Power Control for Distribution Grid Voltage Regulation with Photovoltaic Systems," 2019 IEEE PES GTD Grand International Conference and Exposition Asia (GTD Asia), 2019, pp. 136-141, doi: 10.1109/GTDAsia.2019.8715903.

[11] H. Wang, et al., "Topology and Modulation Scheme of a Three-Level Third-Harmonic Injection Indirect Matrix Converter," in IEEE Transactions on Industrial Electronics, vol. 64, no. 10, pp. 7612-7622, Oct. 2017, doi: 10.1109/TIE.2017.2694386.

[12] G. Zhang, H. Wang, and C. Zhang, "Modulated Model Predictive Control for 3TSMC," 2020 IEEE Energy Conversion Congress and Exposition (ECCE), 2020, pp. 4173-4177, doi: 10.1109/ECCE44975.2020.9236271.

[13] H. Hu, S. Harb, N. Kutkut, I. Batarseh, and Z. J. Shen, "A Review of Power Decoupling Techniques for Microinverters with Three Different Decoupling Capacitor Locations in PV Systems," in IEEE Transactions on Power Electronics, vol. 28, no. 6, pp. 2711-2726, June 2013, doi: 10.1109/TPEL.2012.2221482.

[14] D. Pilakkat and S. Kanthalakshmi, "An improved P\&O algorithm integrated with artificial bee colony for photovoltaic systems under partial shading conditions," Solar Energy, vol. 178, pp. 37-47, March 2018, doi: 10.1016/j.solener.2018.12.008.

[15] C. Lu, B. Zhou, J. Lei, and J. Shan, "Mains Current Distortion Suppression for Third-Harmonic Injection TwoStage Matrix Converter," in IEEE Transactions on Power Electronics, vol. 36, no. 6, pp. 7202-7211, June 2021, doi: 10.1109/TPEL.2020.3039596.

[16] J. Schonberger, "A single phase multi-string PV inverter with minimal bus capacitance," 2009 13th European Conference on Power Electronics and Applications, 2009, pp. 1-10.

[17] A. C. Nanakos, E. C. Tatakis, and N. P. Papanikolaou, "A Weighted-Efficiency-Oriented Design Methodology of Flyback Inverter for AC Photovoltaic Modules," in IEEE Transactions on Power Electronics, vol. 27, no. 7, pp. 3221-3233, July 2012, doi: 10.1109/TPEL.2011.2182211.

[18] H. Wang, et al., "Two-Stage Matrix Converter Based on Third-Harmonic Injection Technique," in IEEE Transactions on Power Electronics, vol. 31, no. 1, pp. 533-547, Jan. 2016, doi: 10.1109/TPEL.2015.2413452.

[19] C. Lu, B. Zhou, J. Lei and J. Shan, "Active Damping Control Strategy of Hybrid Active Third-Harmonic Injection Matrix Converter via Modifying Third-Harmonic Injection Reference Current and Output Reference Current," 2019 22nd International Conference on Electrical Machines and Systems (ICEMS), 2019, pp. 1-6, doi: 10.1109/ICEMS.2019.8922136.

[20] A. Mohapatra, B. Nayak, P. Das, and K. B. Mohanty, "A review on MPPT techniques of PV system under partial shading condition," Renewable and Sustainable Energy Reviews, vol. 80, pp. 854-867, December 2017, doi: 10.1016/j.rser.2017.05.083.

[21] A. Mohapatra, B. Nayak, and C. Saiprakash, "Adaptive Perturb \& Observe MPPT for PV System with Experimental Validation," 2019 IEEE International Conference on Sustainable Energy Technologies and Systems (ICSETS), 2019, pp. 257-261, doi: 10.1109/ICSETS.2019.8744819.

[22] J. Feng, H. Wang, J. Xu, M. Su, W. Gui, and X. Li, "A Three-Phase Grid-Connected Microinverter for AC Photovoltaic Module Applications," in IEEE Transactions on Power Electronics, vol. 33, no. 9, pp. 7721-7732, Sept. 2018, doi: 10.1109/TPEL.2017.2773648.

[23] H. Wang, et al., "Active third-harmonic injection indirect matrix converter with dual three-phase outputs," IET Power Electron, vol. 9, no. 4, pp. 657-668, 2016, doi:10.1049/iet-pel.2014.0703.

[24] T. Suyata, S. Po-Ngam, and C. Tarasantisuk, "The active power and reactive power control for three-phase gridconnected photovoltaic inverters," 2015 12th International Conference on Electrical Engineering/Electronics, Computer, Telecommunications and Information Technology (ECTI-CON), 2015, pp. 1-6, doi: 10.1109/ECTICon.2015.7207066.

[25] T. Suyata and S. Po-Ngam, "Simplified active power and reactive power control with MPPT for three-phase gridconnected photovoltaic inverters," 2014 11th International Conference on Electrical Engineering/Electronics, Computer, Telecommunications and Information Technology (ECTI-CON), 2014, pp. 1-4, doi: 10.1109/ECTICon.2014.6839804. 